\title{
Development of a simulation model to study tool loads in pcBN when machining AISI 316L
}

\author{
Mathias Agmell ${ }^{1}$. Volodymyr Bushlya ${ }^{1}$ - Sampsa V. A. Laakso ${ }^{1}$. Aylin Ahadi ${ }^{1}$. Jan-Eric Ståhl ${ }^{1}$
}

Received: 13 October 2017 / Accepted: 24 January 2018 / Published online: 26 February 2018

(C) The Author(s) 2018. This article is an open access publication

\begin{abstract}
This paper presents the development of a FE-simulation model to predict the mechanical stresses and thermal loads that a cutting tool of polycrystalline cubic boron nitride ( $\mathrm{pcBN}$ ) is subjected to, when machining AISI 316L. The serrated chip formation of AISI 316L has a major impact on the periodic loads acting on the cutting tool. Therefore, it is vital to correctly model this serrated chip formation. One of the major difficulties with FE-simulations of metal cutting is that the extreme deformations in the workpiece material, often leads to a highly distorted mesh. This paper uses the Coupled EulerianLagrangian (CEL) formulation in Abaqus/Explicit, where the workpiece is modelled with the Eulerian formulation and the cutting tool by the Lagrangian one. This CEL formulation enables to completely avoid mesh distortion. To capture the chip serration process, the workpiece material is described with the Johnson-Cook damage model. The FE-simulation results are validated via comparison of the modelled cutting forces, chip serration frequency, and contact length against experimental ones.
\end{abstract}

Keywords Metal cutting $\cdot$ FEM $\cdot$ Tool stresses $\cdot$ pcBN $\cdot$ CEL

\section{Nomenclature}

\section{Symbol Description (Unit)}

$A \quad$ Initial yield stress in Johnson-Cook $\left(\mathrm{N} / \mathrm{mm}^{2}\right)$

$A_{c l} \quad$ Axial force acting on the clearance face $(\mathrm{N})$

$A_{r} \quad$ Axial force acting on the rake face (N)

$b \quad$ Chip width (mm)

然

Mathias Agmell

mathias.agmell@iprod.lth.se

Volodymyr Bushlya

volodymyr.bushlya@iprod.lth.se

Sampsa V. A. Laakso

sampsa.laakso@iprod.lth.se

Aylin Ahadi

aylin.ahadi@mek.lth.se

Jan-Eric Ståhl

jan-eric.stahl@iprod.lth.se

1 Department of Mechanical Engineering, Lund University, Lund, Sweden
$B \quad$ Strain hardening modulus in Johnson-Cook $\left(\mathrm{N} / \mathrm{mm}^{2}\right)$

C Strain-rate dependence coefficient in Johnson-Cook

$C_{p, w} \quad$ Specific heat capacity of the workpiece material $(\mathrm{J} /(\mathrm{kg} \cdot \mathrm{K}))$

$C_{p, t} \quad$ Specific heat capacity of the tool material $(\mathrm{J} /(\mathrm{kg} \cdot \mathrm{K}))$

$\mathrm{Cr} \quad$ Cutting resistance $\left(\mathrm{N} / \mathrm{mm}^{2}\right)$

$D \quad$ Scalar stiffness degradation

$D_{1-5} \quad$ Constants in the Johnson-Cook damage model

$E_{w} \quad$ Young's modulus of the workpiece material $\left(\mathrm{N} / \mathrm{mm}^{2}\right)$

$E_{t} \quad$ Young's modulus of the tool material $\left(\mathrm{N} / \mathrm{mm}^{2}\right)$

$e_{2} \quad$ Segment of serrated chip (mm)

$f \quad$ Feed $(\mathrm{mm} / \mathrm{rev})$

$f_{s} \quad$ Segmentation frequency $(\mathrm{Hz})$

$F_{c} \quad$ Primary cutting force (N)

$F_{f} \quad$ Feed force $(\mathrm{N})$

$F_{p} \quad$ Perpendicular force (N)

$G_{f} \quad$ Hillerborg's fracture energy $(\mathrm{J} / \mathrm{m})$

$h_{1} \quad$ Theoretical chip thickness, uncut chip thickness (mm) 
$h_{2} \quad$ True chip thickness, deformed chip thickness (mm)

$k_{w} \quad$ Thermal conductivity of the workpiece material $(\mathrm{W} /(\mathrm{m} \cdot \mathrm{K}))$

$k_{t} \quad$ Thermal conductivity of the tool material $(\mathrm{W} /(\mathrm{m} \cdot \mathrm{K}))$

$l_{r} \quad$ Contact length on the rake face $(\mathrm{mm})$

$m \quad$ Thermal softening coefficient in Johnson-Cook

$n \quad$ Strain hardening exponent in Johnson-Cook

$P \quad$ Hydrostatic stress $\left(\mathrm{N} / \mathrm{mm}^{2}\right)$

$r_{\beta} \quad$ Edge radius $\mathrm{mm}$

$r_{\varepsilon} \quad$ Nose radius $\mathrm{mm}$

$T_{c l} \quad$ Tangential force acting on the clearance face (N)

$T_{r} \quad$ Tangential force acting on the rake face (N)

$u \quad$ Plastic displacement (mm)

$u_{f} \quad$ Plastic displacement at failure (mm)

u Displacement vector $(\mathrm{mm})$

$v_{c} \quad$ Cutting speed $(\mathrm{m} / \mathrm{min})$

$v_{x} \quad$ Velocity in $\mathrm{x}$-direction $(\mathrm{m} / \mathrm{min})$

$v_{y} \quad$ Velocity in y-direction $(\mathrm{m} / \mathrm{min})$

$v_{z} \quad$ Velocity in z-direction $(\mathrm{m} / \mathrm{min})$

$\alpha \quad$ Clearance angle

$\alpha_{L, w} \quad$ Thermal expansion of the workpiece material $\left(\mathrm{K}^{-1}\right)$

$\gamma$

$\varepsilon$

Rake angle

Strain

Johnson-Cook fracture strain

Strain increment

Strain rate $\left(\mathrm{s}^{-1}\right)$

Reference strain rate $\left(\mathrm{s}^{-1}\right)$

Dimensionless strain rate

Major cutting angle

Temperature (K)

Bulk temperature of the workpiece material $(\mathrm{K})$

Melt temperature of the workpiece material (K)

Homologous temperature

Inclination angle

Chip compression ratio

Sliding friction coefficient

Poisson's ratio of the workpiece material

Poisson's ratio of the tool material

Density of the workpiece material $\left(\mathrm{kg} / \mathrm{m}^{3}\right)$

Density of the tool material $\left(\mathrm{kg} / \mathrm{m}^{3}\right)$

Flow stress $\left(\mathrm{N} / \mathrm{mm}^{2}\right)$

Maximal global principal stress $\left(\mathrm{N} / \mathrm{mm}^{2}\right)$

Maximum global effective stress $\left(\mathrm{N} / \mathrm{mm}^{2}\right)$

Stress triaxiality $\left(\mathrm{N} / \mathrm{mm}^{2}\right)$

Normal stress along the tool-chip interface $\left(\mathrm{N} / \mathrm{mm}^{2}\right)$

Uniaxial yield stress of the workpiece material $\left(\mathrm{N} / \mathrm{mm}^{2}\right)$

Stress vector $\left(\mathrm{N} / \mathrm{mm}^{2}\right)$ $\tau_{f} \quad$ Frictional stress along the tool-chip interface $\left(\mathrm{N} / \mathrm{mm}^{2}\right)$

$\tau_{y} \quad$ Shear strength $\left(\mathrm{N} / \mathrm{mm}^{2}\right)$

$\omega \quad$ Scalar damage parameter

\section{Introduction}

Cemented carbide is the most common material for tooling in metal cutting [29]. Its main constituents, tungsten and cobalt, are classified as critical raw materials [3], and therefore a search for alternative tooling, like polycrystalline cubic boron nitride ( $\mathrm{pcBN}$ ), is on an industrial agenda. Eighteen percent of cemented carbide is used for machining stainless steels (ISO M group) [2] where AISI 316L is one of the major material representatives.

Machining is one of the major manufacturing processes in engineering production and it plays an important role in modern industry. The understanding of the metal cutting process is difficult due to the complex mechanics of the deformation taking place. In a typical machining process, the workpiece material undergoes severe deformation with large strains up to $1-2$ in the primary deformation zone and above 3 in the secondary deformation zone, strain rates up to $10^{6} \mathrm{~s}^{-1}$ and temperatures above $1000{ }^{\circ} \mathrm{C}$ [8]. Due to these extreme conditions present in metal cutting, it is difficult to experimentally measure interesting aspects during the process. While cemented carbide is known to handle such extreme thermal and mechanical loads, it is not given that alternative tooling materials like $\mathrm{pcBN}$ are capable to cope with these conditions. Direct measurement of such loads is often impossible, and therefore, in recent years, the finite element modelling technique has become an important numerical tool for simulating the machining process. Constitutive models describing the material flow behaviour as a function of strain hardening, strain rate hardening, and thermal softening are required in order to capture the plasticity behaviour of the workpiece, during the conditions encountered in the machining process [13, 32]. In finite element simulations, there are two types of formulations, Eulerian and Lagrangian. In the Eulerian formulation, the mesh is fixed in space and the material flows through it, while in the Lagrangian formulation the mesh is attached to the material and follows its deformation. The advantage of the Eulerian formulation is that the problem with severe element distortion is completely avoided. However, a pure Eulerian formulation requires prior knowledge of the chip geometry and chip-tool contact length, thereby restricting the application range [39]. The advantages of the Lagrangian formulation in metal cutting simulations is that the chip geometry does not have to be predetermined. One of the disadvantages of the Lagrangian formulation is that due to the large deformations occurring 
in a machining process it will inevitably lead to excessive element distortion in the mesh. Finite element models that use this type of formulation require a chip separation criterion to enable for the chip to come off the workpiece [6, 16]. Remeshing can also be adopted to reduce the element distortion [9, 30, 37]. Remeshing also leads to a significant increase in the CPU computing time and will decrease the result accuracy because of the data transfer from the old mesh to the new $[16,33]$.

To overcome the limitations pointed out above, a technique called Coupled Eulerian-Lagrangian (CEL) can be used. It consists of both Eulerian and Lagrangian formulations, where typically the workpiece is modelled with Eulerian formulation and the tool is described by a Lagrangian formulation. The CEL formulation has been successfully adopted in metal cutting simulations by $[14,15$, 20, 28] with promising results.

In this paper, the CEL method in Abaqus/Explicit v6.142 is used to model 3D orthogonal cutting of a workpiece consisting of AISI 316L with a pcBN insert. The tool was modelled with a Lagrangian formulation and the workpiece by a Eulerian formulation. This will ensure that issues with mesh distortion will be avoided and in addition no chip separation must be introduced. The focus of this paper is to examine the possibility to use the CEL formulation to model a serrated chip formation. In order to enable correct description of AISI 316L behaviour in machining, formation of serrated chips in particular. This opens up possibility to study dynamic loads acting on the tool during the periodic chip serration and to evaluate its effects on the induced mechanical and thermal fields in the tooling.

\section{Machining mechanics}

The resulting cutting force in a machining operation can be decomposed into the three components. The force parallel to the cutting speed direction is the primary cutting force $F_{c}$; this is in most cases the highest component of the three forces. The force acting in the axial feed direction is the feed force $F_{f}$; this is often the second highest component. The third of the components is called the passive force $F_{p}$ and acts in the radial feed direction. In the two-dimensional case or orthogonal cutting case, the only active forces are the primary cutting force $F_{c}$ and the feed force $F_{f}$.

A turning process can be divided into three intervals: engagement phase, stationary phase, and exit phase. In the engagement phase, the cutting tool and the workpiece get in contact and transient cutting forces occur as the contact pressure increases at the interface. In the stationary phase, a steady state condition for the cutting forces is achieved. For workpiece materials that form serrated chips, a periodic behaviour of the cutting forces occurs in this phase. This is the phase where a machining operation for the major material removal takes place. In the exit phase, the cutting tool disengages from the workpiece. The cutting forces are also transient as they decrease due to reduction of contact area between the cutting tool and the workpiece.

The mechanical load to which a cutting tool is subjected to has either direct or an indirect effect on the wear and failures of various types that can occur. The mechanical stresses that affect the cutting tool have a direct effect on the occurrence of damages to it such as flaking, crack formation, chipping, plastic deformation, and breakage [35]. The highest levels of stress appear on the boundary surface of the cutting tool. The maximum global principal stress $\sigma_{1}$ gives rise to tensile stresses and respective tool failures usually found on the rake face of the tool. The maximum effective stress $\sigma_{e}$ gives rise to compressive stresses often occurring on the flank face of the tool, see Fig. 1. The development of crack formation, tool chipping, and breakage is largely a function of the maximum principal stress level $\sigma_{1}$. The compressive stress $\sigma_{e}$ is about the same level as the effective stress (von Mises), with opposite sign. The risk of plastic deformation and of damage through tool fracture tends to be controlled by the level of effective stress $\sigma_{e}[35]$.

\section{Experimental setup}

Machining tests were done on SMT 500 CNC lathe. Orthogonal cutting of AISI 316L stainless steel tube having the wall thickness of $b=2.5 \mathrm{~mm}$ was performed at the fixed cutting speed of $v_{c}=250 \mathrm{~m} / \mathrm{min}$. The feed ranged from $f=0.005 \mathrm{~mm} / \mathrm{rev}$ to $f=0.25 \mathrm{~mm} / \mathrm{rev}$. Machining was done with CBN170 tool grade (SECO Tools) of DNGN110308 geometry. CDJNL3225P11 toolholder was milled to modify the tool angles to the major cutting edge angle $\kappa=90^{\circ}$, inclination angle $\lambda=0^{\circ}$. New cutting

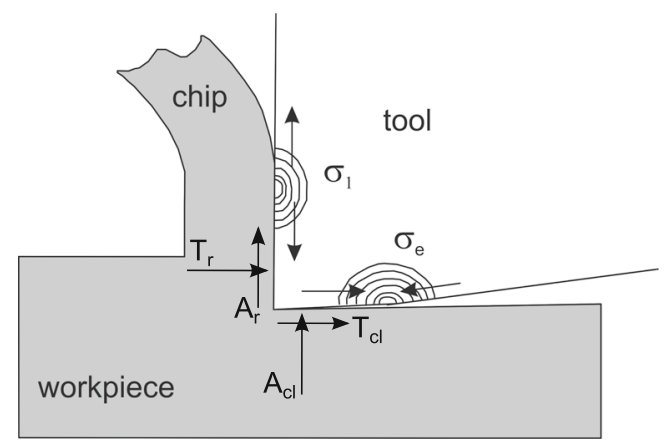

Fig. 1 The location of the maximum principal stress $\sigma_{1}$, the maximum effective stress $\sigma_{e}$ in the cutting tool in a turning operation 
edge was used for every machining test for the given feeds. Tool-chip contact dimensions were detected and measured with SEM LEO 1560. Cutting forces were measured with the Kistler 9129AA dynamometer. Chips were collected, mounted, polished, and etched. In Fig. 2, the setup for the experimental cutting tests is presented.

\section{Numerical modelling}

\subsection{Thermo-physical behaviour}

The high levels of strain, strain rate, temperature, and temperature rate that occurs in the workpiece during a machining operation, have to be accounted for in order to accurately model the plasticity behaviour in workpiece material. For this reason, the Johnson-Cook plasticity model is used in this study, developed by Johnson and Cook in [18]. This plasticity model is commonly employed when modelling metal cutting with the use of FEM, such as $[5,7$, 24, 30]. The Johnson-Cook constitutive law is presented in Eq. 1

$\bar{\sigma}=\left(A+B \bar{\varepsilon}^{n}\right)\left(1+C \ln \dot{\bar{\varepsilon}}^{*}\right)\left(1-\theta^{* m}\right)$

where $\bar{\sigma}$ is the equivalent stress, $\bar{\varepsilon}$ is the equivalent plastic strain, $\dot{\bar{\varepsilon}}^{*}=\dot{\bar{\varepsilon}} / \dot{\bar{\varepsilon}}_{0}$ is the dimensionless plastic strain rate, $\dot{\bar{\varepsilon}}$ is the equivalent plastic strain rate, $\dot{\bar{\varepsilon}}_{0}$ is the reference strain rate, $A$ is the initial yield stress, $B$ is the hardening modulus, $C$ is the strain rate dependency coefficient, $n$ is the strainhardening exponent, $m$ is the thermal softening coefficient. The homologous temperature $\theta^{*}$ is defined as $\theta^{*}=(\theta-$ $\left.\theta_{0}\right) /\left(\theta_{m}-\theta_{0}\right)$ where $\theta$ is the process temperature, $\theta_{m}$ is the melting temperature and $\theta_{0}$ is the reference temperature of the workpiece. The workpiece was considered as AISI $316 \mathrm{~L}$

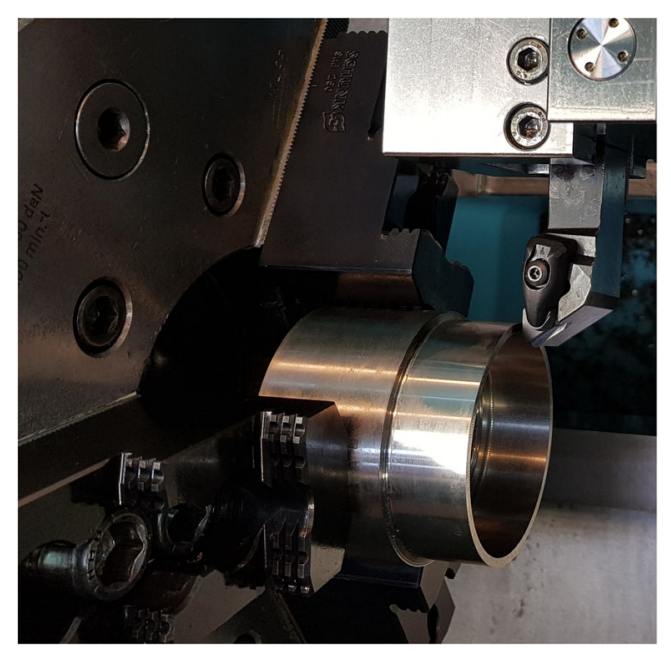

Fig. 2 Setup of the experimental force measurements for orthogonal cutting tests
Table 1 Johnson-Cook parameters to model the plasticity behaviour of the AISI 316L [12]

\begin{tabular}{llllll}
\hline$A[\mathrm{MPa}]$ & $B[\mathrm{MPa}]$ & $C$ & $n$ & $m$ & $\dot{\bar{\varepsilon}}_{0}$ \\
\hline 305 & 1161 & 0.01 & 0.61 & 0.517 & 1 \\
\hline
\end{tabular}

stainless steel and the cutting tool was modelled as CBN170 tool grade. The Johnson-Cook parameters used for the workpiece are specified in Table 1. The considered physical properties both for workpiece and cutting tool are presented in Table 2. Elastic properties of CBN170 were measured in pulse-echo regime with Olympus 38DL PLUS ultrasonic precision thickness gauge. To model the elastic behaviour of AISI 316L steel a temperature dependent Young's modulus $E_{w}$ given by experimental data from [1], reported in Table 3, were used. Thermal properties of CBN170 were measured in the temperature range of 290 to $1373 \mathrm{~K}$ with light flash apparatus Netzsch LFA 467HT HyperFlash and is presented in Table 4. The heat transfer coefficient at the contact interface between the workpiece and cutting tool is set to $1000 \mathrm{~kW} /\left(\mathrm{m}^{2} \cdot \mathrm{K}\right)$ adopted from $[27,38]$.

\subsection{Chip formation and segmentation criterion}

The criterion used for damage initiation was the JohnsonCook damage model, presented by Johnson and Cook in [19]. This criterion is a commonly used criterion for metal cutting simulations, used for example in $[7,24,30,40]$. The Johnson-Cook fracture strain $\bar{\varepsilon}_{f}$, is given by Eq. 2

$\bar{\varepsilon}_{f}=\left(D_{1}+D_{2} \exp \left(D_{3} \sigma^{*}\right)\right)\left(1+D_{4} \ln \dot{\bar{\varepsilon}}^{*}\right)\left(1+D_{5} \theta^{*}\right)$

where $D_{1}, \ldots, D_{5}$ are material constants and $\sigma^{*}=P / \bar{\sigma}$ is the stress triaxiality where $P$ represents the hydrostatic stress.

The damage in a given element is initiated when the scalar damage parameter $\omega$ exceeds unity. This parameter is based on a cumulative law defined as

$\omega=\sum_{i=1}^{k}\left(\frac{\Delta \bar{\varepsilon}}{\bar{\varepsilon}_{f}}\right)_{i}$

where $\Delta \bar{\varepsilon}$ is the increment of equivalent plastic strain during an increment $i . \bar{\varepsilon}_{f}$ was set to 1.6 in order to predict a correct primary cutting force according to experimental results.

When material damage is initiated, the stress-strain relationship of Eq. 1 alone does not accurately represent the material's behaviour, i.e. curve b to c' in Fig. 3 . Continuing to use the stress-strain relation introduces a strong mesh dependency based on strain localization, such that the energy dissipated decreases as the mesh is refined. A different approach is required to follow the strain-softening branch of the stress-strain response curve. Hillerborg's 
Table 2 Physical properties of AISI 316L stainless steel [36, 38] and CBN170 tool grade

\begin{tabular}{ll}
\hline AISI 316L & Density $\left(\mathrm{kg} / \mathrm{m}^{3}\right): \rho_{w}(\theta)=7921-0.614 \theta+0.0002 \theta^{2}$ \\
& Poisson's ratio: $v_{w}=0.30$ \\
& Melting point $(\mathrm{K}): \theta_{m}=1672$ \\
& Thermal conductivity $(\mathrm{W} /(\mathrm{m} \cdot \mathrm{K})): k_{w}(\theta)=14.307+0.0181 \theta-6 \cdot 10^{-6} \theta^{2}$ \\
& Specific heat $\left(\mathrm{J} /(\mathrm{kg} \cdot \mathrm{K}): C_{p, w}(\theta)=440.79+0: 5807 \theta-0.001 \theta^{2}+7 \cdot 10^{-7} \theta^{3}\right.$ \\
& Thermal expansion $\left(\mathrm{K}^{-1}\right): \alpha_{L, w}=16.0 \cdot 10^{-6}$ \\
CBN170 tool grade & Density $\left(\mathrm{kg} / \mathrm{m}^{3}\right): \rho_{t}=3940$ \\
& Young's modulus $(\mathrm{GPa}): E_{t}=610$ \\
& Poisson's ratio: $v_{t}=0.155$ \\
&
\end{tabular}

fracture energy, $G_{f}$ presented in [17] is used to reduce mesh dependency by creating a stress-displacement response after damage is initiated. The fracture energy is then given by Eq. 4.

$G_{f}=\int_{\bar{\varepsilon}_{0}}^{\bar{\varepsilon}_{f}} L \bar{\sigma} \mathrm{d} \bar{\varepsilon}=\int_{0}^{\bar{u}_{f}} \bar{\sigma} \mathrm{d} \bar{u}$

where $L$ is the characteristic length associated with an integration point. $\bar{\varepsilon}_{0}$ is the equivalent plastic strain at damage initiation and $\bar{\varepsilon}_{f}$ is the equivalent plastic strain when the material is fully degraded corresponding to point $b$ and $\mathrm{f}$ respectively in Fig. 3 and $\bar{u}_{f}$ and $\bar{\sigma}$ are the equivalent plastic displacement and flow stress. The fracture energy of AISI 316L is considered to be equal to $3.2 \mathrm{Jmm}^{-1}$ according to [31]. The degradation of the material upon damage is considered to follow an exponential behaviour and given by Eq. 5.

$D=1-\exp \left(-\int_{0}^{\bar{u}_{f}} \frac{\bar{\sigma} \mathrm{d} \bar{u}}{G_{f}}\right)$

The formulation of the model ensures that the energy dissipated during the damage evolution process is equal to $G_{f}$, and the scalar stiffness degradation $D$, approaches asymptotically to one at an infinite equivalent plastic displacement. The stiffness degradation effect applies damage to all stiffness components equally according to Eq. 6. When the stiffness degradation $D$, reaches 0.5 the material softening stops, visualized by point $\mathrm{c}$ and start to follow the curve c-e in Fig. 3.

$\sigma=(1-D) \bar{\sigma}$

\subsection{Interaction modelling}

A numerical modelling of the contact at the tool-chip interface has to be used in order to constraint the two bodies from penetrate each other. This is performed by a contact algorithm, which upholds the surfaces of the two bodies in contact. In addition, there has to be a friction model which is able to describe the tribological conditions at the contact interface. The contact algorithm used in Abaqus/explicit for CEL interaction is based on an enhanced immersed boundary method. In this method, the Lagrangian structure occupies void regions inside the Eulerian mesh. The contact algorithm automatically computes and tracks the interface between the Lagrangian structure and the Eulerian materials. The friction model used is a combined sliding and sticking formulation, where an upper boundary controls when sticking friction is active, this upper boundary is set to the shear strength of the workpiece material. The sliding zone is modelled with Coulomb friction and the friction coefficient is set to 0.57 , which has been adopted from [22]. The combined fiction model used in this present study is presented in Eq. 7.

$\tau_{f}=\min \left(\mu \sigma_{n}, \tau_{y}\right)$

where $\tau_{f}$ is the frictional stress, $\mu$ is the fiction coefficient, $\sigma_{n}$ is the normal stress and $\tau_{y}$ is the shear strength of the workpiece, which is defined as $\tau_{y}=\sigma_{y} / \sqrt{3}$ where $\sigma_{y}$ is the uniaxial yield stress.

\subsection{Finite element model}

The finite element model consists of two parts a cutting tool with a Lagrangian formulation and an euler-space with an Eulerian formulation. The euler-space part had an element edge length of $10 \mu \mathrm{m}$ and consisted of a total of

Table 3 Temperature dependence of Young's modulus in AISI 316L steel Table 3

\begin{tabular}{lllllllll}
\hline Temperature, $\theta(\mathrm{K}):$ & 293 & 423 & 533 & 623 & 698 & 753 & 813 & 923 \\
\hline Young's modulus, $E_{w}(\mathrm{GPa}):$ & 210.3 & 191.7 & 180.0 & 191.0 & 188.2 & 186.2 & 156.5 & 113.7 \\
\hline
\end{tabular}


Table 4 Temperature dependence of thermal conductivity and specific heat capacity in CBN170 tool grade

\begin{tabular}{lll}
\hline Temperature & Specific heat & Thermal conductivity \\
$\theta(\mathrm{K})$ & $C_{p, t}(\mathrm{~J} / \mathrm{kg} \cdot \mathrm{K})$ & $k_{t}(\mathrm{~W} /(\mathrm{m} \cdot \mathrm{K}))$ \\
\hline 298 & 652 & 53.388 \\
373 & 806 & 55.178 \\
473 & 983 & 57.355 \\
573 & 1114 & 57.888 \\
673 & 1211 & 57.879 \\
773 & 1273 & 56.618 \\
873 & 1326 & 55.212 \\
973 & 1360 & 53.388 \\
1073 & 1383 & 51.400 \\
1173 & 1396 & 49.274 \\
1273 & 1396 & 46.703 \\
1373 & 1400 & 44.628 \\
\hline
\end{tabular}

3360000 elements. The element size of $10 \mu \mathrm{m}$ has been chosen, in order to get a smooth and reliable effective stress distribution in the tool. The euler-space had the element type EC3D8RT, which is an 8-node thermally coupled linear Eulerian brick element. The cutting tool had an element edge length of $20 \mu \mathrm{m}$ at the cutting interface and the size of the elements at Region C' was $0.2 \mathrm{~mm}$. The cutting tool contained a total of 407110 elements of the element type C3D4T, which is a 4-node linear Lagrangian tetrahedron thermo-mechanical element.

The cutting tool had an edge radius, $r_{\beta}=55 \mu \mathrm{m}$, nose radius, $r_{\varepsilon}=0.8 \mathrm{~mm}$ the nose radius was not a part of the cutting depth in order to get a 3D orthogonal cutting condition. A rake angle, $\gamma=0^{\circ}$, clearance angle $\alpha=6^{\circ}$ and the major cutting edge angle $\kappa=90^{\circ}$. A wall thickness, $b=1 \mathrm{~mm}$ and a theoretical chip thickness of $h_{1}=0.20 \mathrm{~mm}$ was simulated. The eulerian-space was initially filled with workpiece material according to the grey area in Fig. 4 the rest of the eulerian-space was considered as a void region.

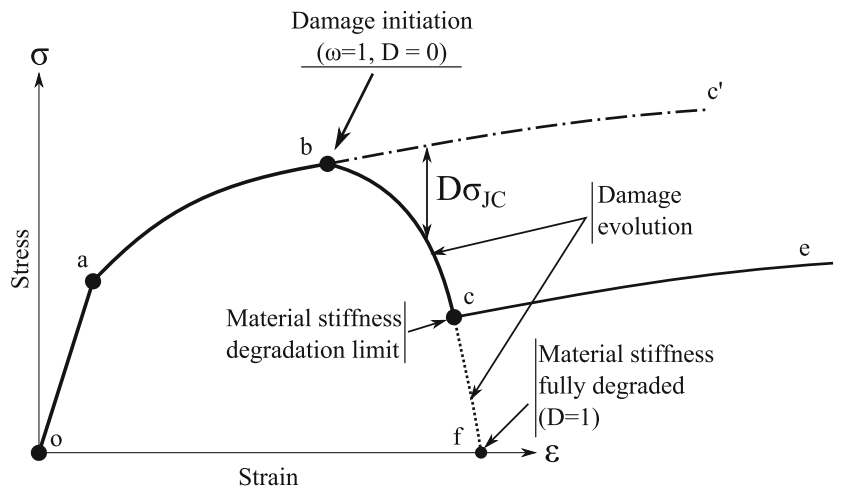

Fig. 3 Stress-strain response of a metal specimen with damage behaviour

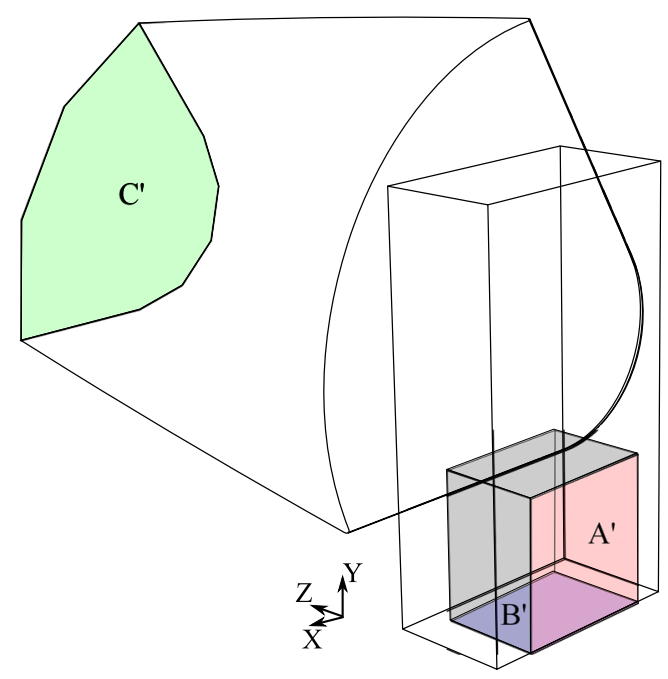

Fig. 4 The initial configuration of the CEL FE model and the mechanical boundary conditions applied to both the workpiece and tool

Figure 4 shows the initial configuration of the CEL-model with visualized mechanical boundary conditions. Region A' was velocity constrained with an inflow of material $v_{z}=v_{c}=250 \mathrm{~m} / \mathrm{min}$ and unbound in all other degrees of freedom. Region B' was velocity constrained with $v_{x}=$ $v_{y}=0$ and unrestricted in all other degrees of freedom. Region C' was considered to be fixed in all displacement degrees of freedom i.e $\boldsymbol{u}=0$.

\section{Results}

In this section the experimental and numerical results is presented. In Fig. 5 the serrated chip formation produced by the FE model is shown. The field shown, is the flow stress degradation in the workpiece caused by the damage modelling of the material.

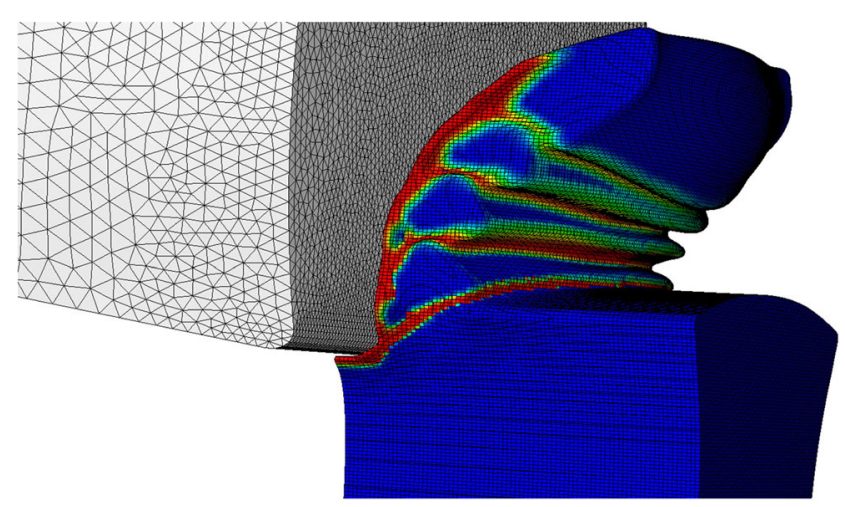

Fig. 5 Serrated chip formation of AISI 316L with $h_{1}=0.2 \mathrm{~mm}$ 


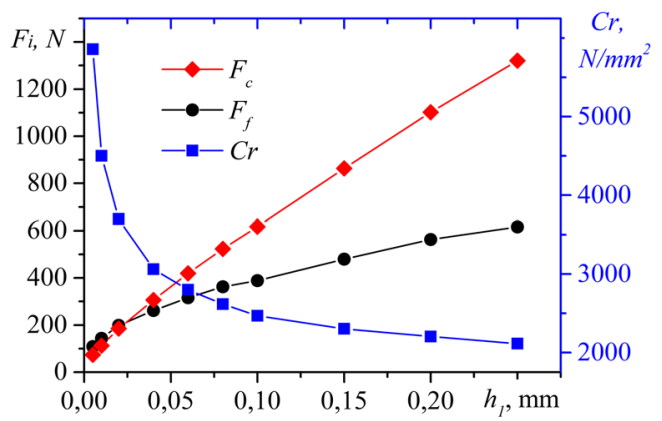

Fig. 6 Experimental cutting force components $F_{c}, F_{f}$, and cutting resistance $\mathrm{Cr}$

\subsection{Cutting forces}

Figure 6 shows the experimentally observed forces within the given range of the theoretical chip thicknesses. Cutting resistance $C r=F_{c} /\left(b h_{1}\right)$ is also presented on the diagram. It can be seen that the $F_{c}$ force component has close to linear behaviour while $F_{f}$ component shows steeper increase at low feeds than at higher feeds. Cutting resistance $\mathrm{Cr}$ also has significantly higher values at low feeds. Both effects are related to a stronger impact of the forces acting on the clearance of the tool at feeds which are comparable with the edge radius $r_{\beta}$.

In Fig. 7 , the experimental and numerical values of both the primary cutting force, $F_{c}$, and the feed force, $F_{f}$, as a function of time is presented, for $h_{1}=0.2 \mathrm{~mm}$. The experimental values are divided by 2.5 in order to compensate for the difference in wall thickness of the tube between the simulation and experimental setup. One can see that the FE model has good correlation for the primary cutting force, but the FE model under predict the feed force. A reason for this could be a combination of the interaction modelling and that the tool edge rapidly get a deformed shape due to a creep behaviour in the tool material, as shown in $[21,25]$.

\subsection{Segmentation frequency}

The two parameters, average chip thickness $h_{2}$ and average size of the segment for the serrated chips $e_{2}$ were measured from the collected and polished chips, see Fig. 8 . Chip compression ratio $\lambda_{h}$ was calculated Fig. 9 from the obtained data regarding the chip morphology. The dependence of $\lambda_{h}$ on the feed can be approximated with a hyperbolic function $\lambda_{h}=1.291+0.021 / h_{1}$. Chip segmentation frequency $f_{s}$ was also determined according to Eq. 8 .

The serrated chip formation of the FE model can be seen in Fig. 5. The segmentation frequency of the FE model was measured to $15.6 \mathrm{kHz}$ and the experimental segmentation frequency for $h_{1}=0.2 \mathrm{~mm}$ was $16.8-17.7 \mathrm{kHz}$. This gives a correlation of $88.1-92.8 \%$ between simulated and experimental results.

$f_{s}=\frac{v_{c} 1000}{e_{2} \lambda_{h} 60}$

\subsection{Contact length}

Contact length on the rake $l_{r}$ was measured for all theoretical chip thicknesses Fig. 9 with the help of scanning electron microscopy. The ratio of the contact length to the uncut chip thickness $l_{r} / h_{1}$ exhibits decreasing trend similar to the chip compression ratio.

The contact length of the FE model was measured by the maximum length of the contact pressure build up on the rake
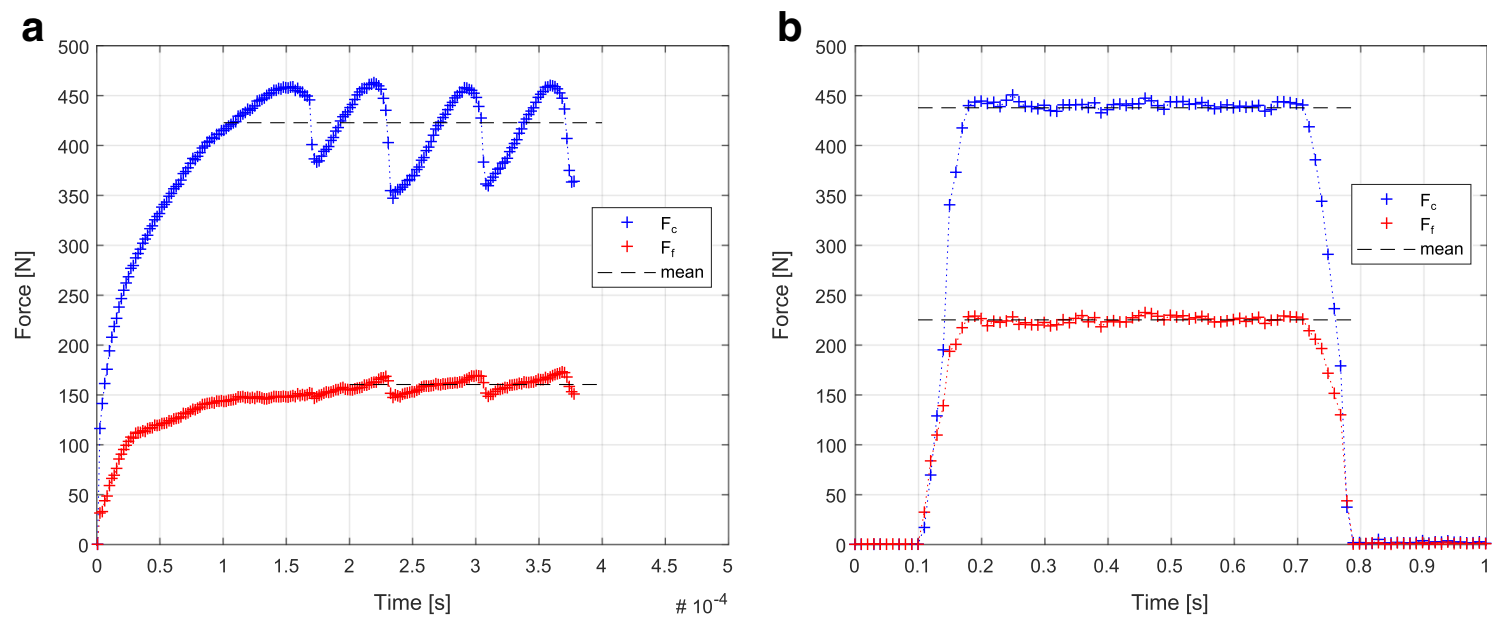

Fig. 7 Primary cutting force and feed force as a function of time for FEM (a) and experimental (b) 
Fig. 8 a Micrograph of the chip cross section. b Data on segment size $e_{2}$ and segmentation frequency $f_{s}$
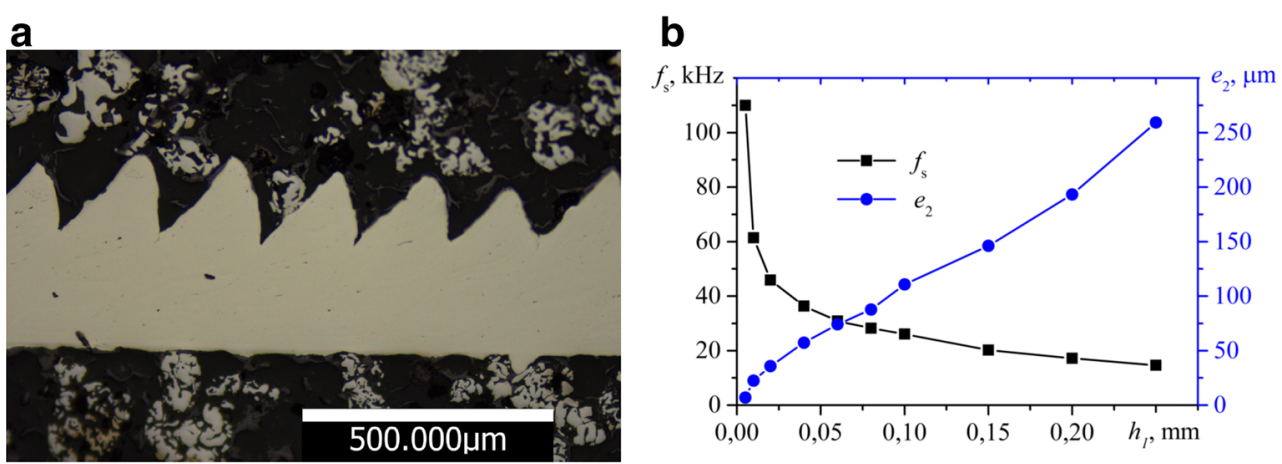

face. Figure 10 shows the contact length and the contact pressure distribution on the rake face of the tool. The contact length of the FE model was measured to $0.364 \mathrm{~mm}$ and the experimental contact length for $h_{1}=0.2 \mathrm{~mm}$ was 0.362 $\mathrm{mm}$. This gives a correlation of $99.4 \%$ between simulated and experimental results.

\subsection{Mechanical loads}

The maximal principal stress experienced by the cutting tool, is located on the rake face of the cutting tool. The cutting tool, has two zones that experience high principal stresses. In Fig. 11a, b the distribution of the principal stress in the cutting tool at the peak value in the engagement phase and at a peak value in the steady state phase are illustrated. High principal stresses at the engagement phase, can be explained by the fact that the cutting tool has no support at the flank face in the initial contact with the workpiece, as shown in [4]. The maximal principal stress during the steady state phase is located further up on the rake face, since contact length between the workpiece and the cutting tool has increased. In Fig. 12 the primary cutting force and the maximal principal stress for an element as a function of time is presented. This element is located in the area where the cutting tool experience high principal stresses during the steady state phase, hence Fig. 12 will not show the maximal principal stress experienced by the tool in the engagement phase. It can be seen that the principal stress has the same frequency as primary cutting force, in the steady state phase.

The location of the maximal effective stress is found at the flank face of the cutting tool. In Fig. 13 the distribution of the von Mises stress in the cutting tool at time $0.18 \mathrm{~ms}$ is shown. Since the maximal effective stress in the cutting tool, does not have a peak during the engagement phase. The area effected by high effective stress during the simulation will be located approximately in the same location in the cutting tool. Figure 14 shows the primary cutting force and maximal effective stress for a node as a function of time. Similar to the maximal principal stress the maximal effective stress has the same frequency as the primary cutting force.

\subsection{Thermal load}

In Fig. 15 shows the temperature distribution at the rake face of the tool at the end of the simulation. This is well below experimental value, for example shown in $[23,26$, 38]. An explanation for this can be that the thermal steady state is reached much later than the steady state condition for the mechanical part, as stated in [38]. In Fig. 16 the nodal temperature with respect to time for a node in the high temperature zone at the rake face is presented. One can see that the temperature increase has a close connection to
Fig. 9 SEM image of the tool-chip contact area $\left(h_{1}=\right.$ $0.08 \mathrm{~mm}$ ) (a) and on chip compression ratio $\lambda_{h}$ and the contact length on the rake $l_{r}$ (b) a

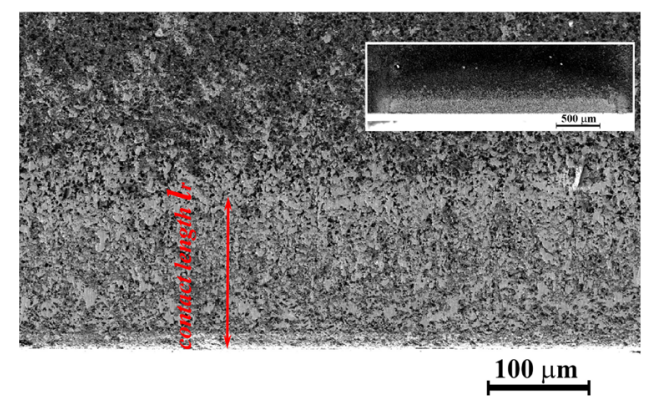

b

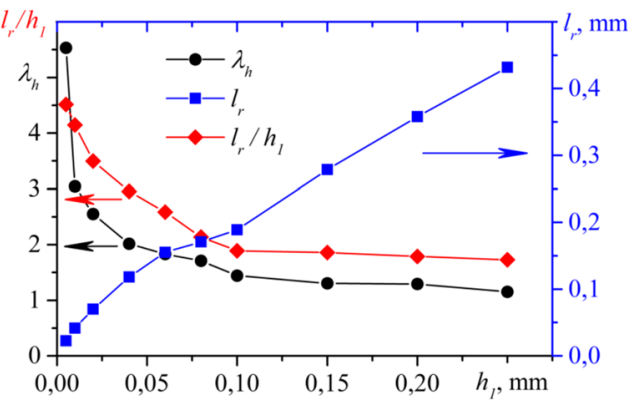


Fig. 10 Contact pressure

distribution and contact length on the rake face $l_{r}$ in FE model

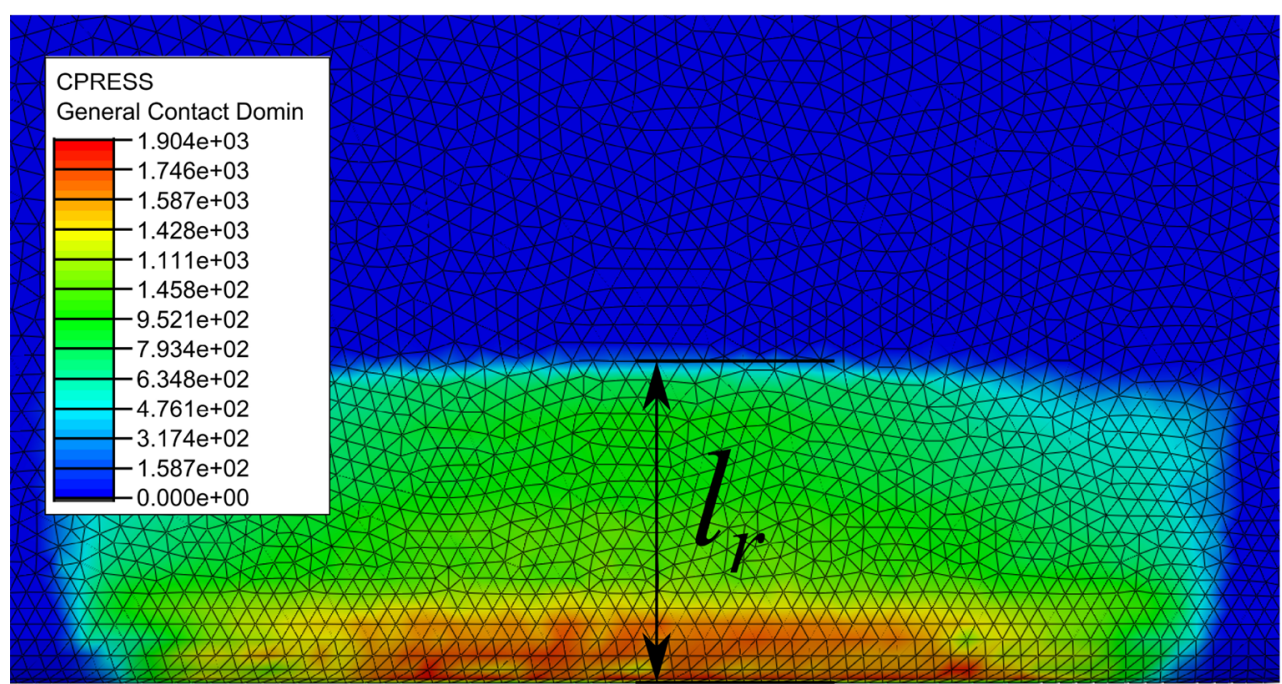

a

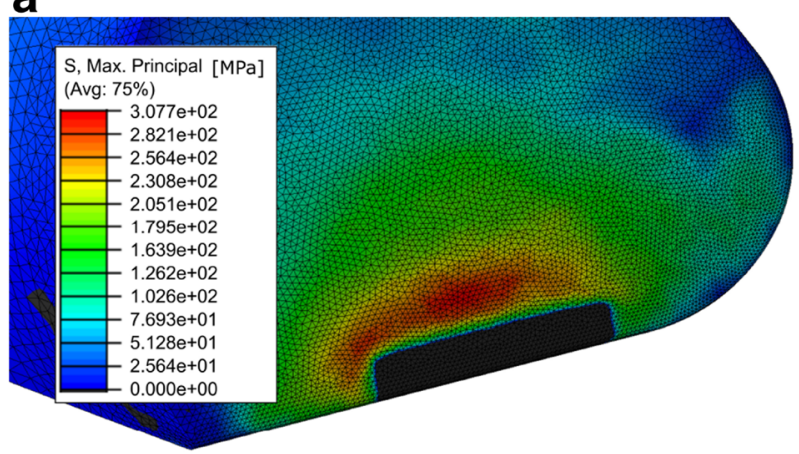

b

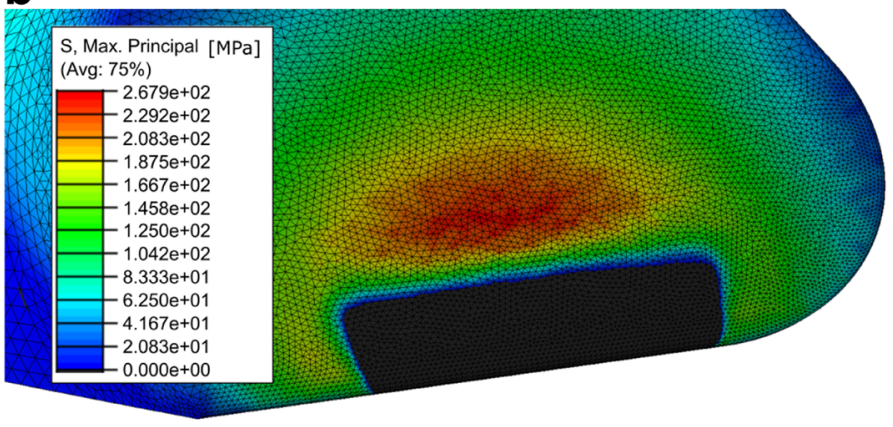

Fig. 11 Maximal principal stress distribution in the cutting tool in the engagement phase (a) and steady state phase (b)

Fig. 12 Primary cutting force and maximal principal stress as a function of time

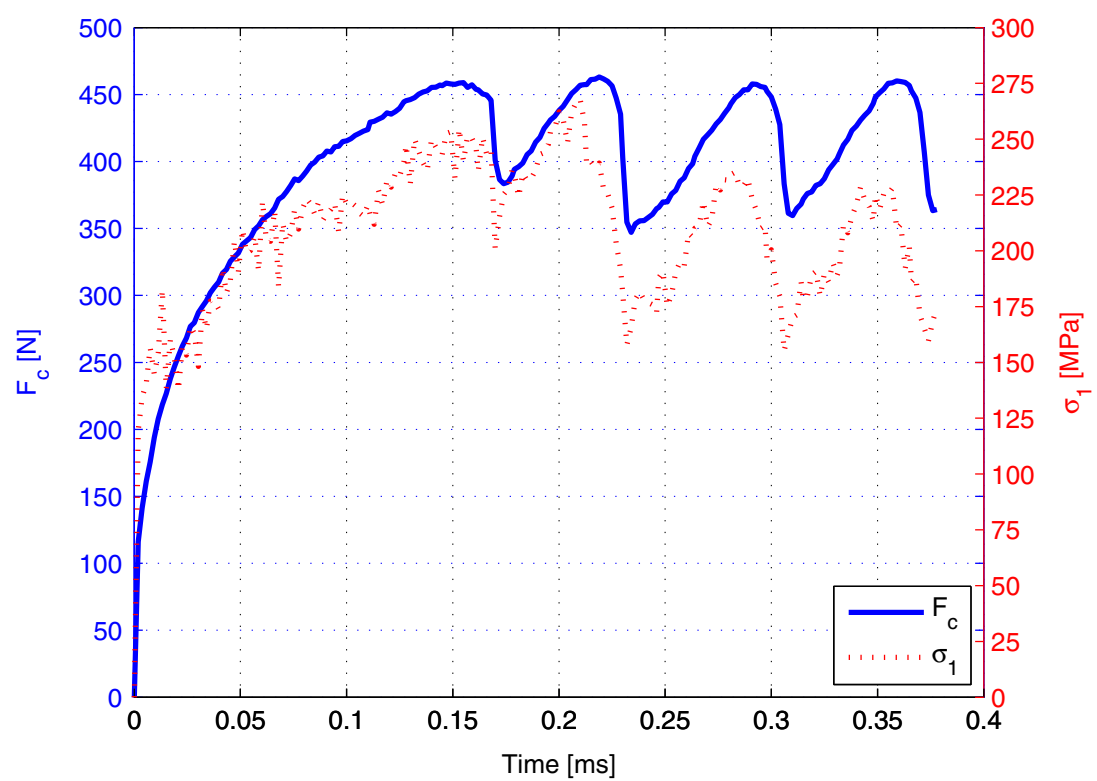


Fig. 13 Distribution of the effective stress at the flank face at time $0.18 \mathrm{~ms}$

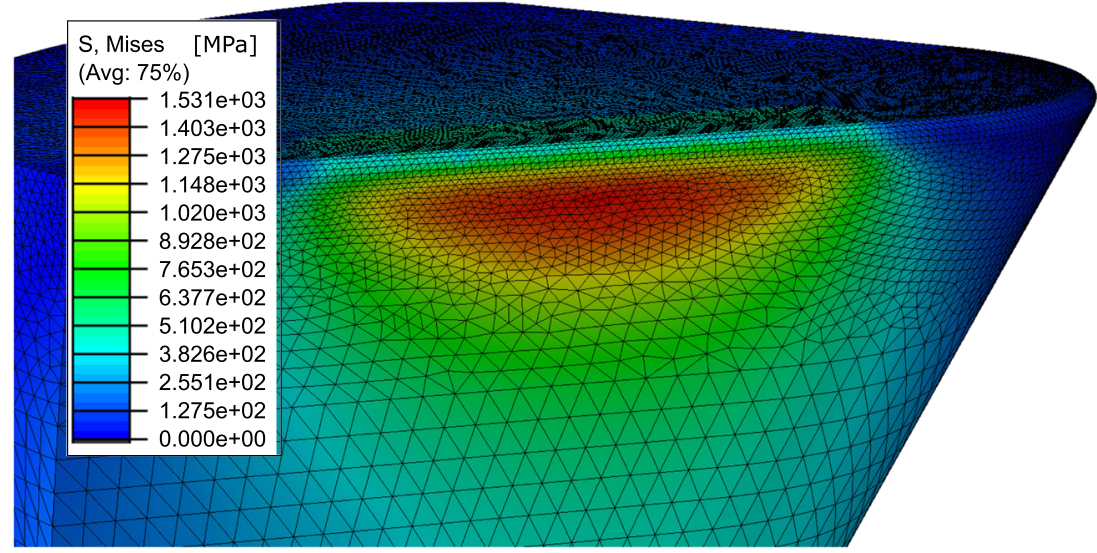

the segmentation of the workpiece, since it has a periodic behaviour with the same frequency as the primary cutting force. Figure 16 clearly shows that no steady state condition in a thermal perspective is achieved within the simulation time. Although it can be of importance to present the distribution of the thermal load affecting the tool. Since this can serve as a starting shape of the thermal load in further investigations, in Fig. 17 the temperature at the middle cross section of the tool-chip interaction area is presented.

\section{Discussion}

This study shows that the CEL formulation is a promising technique to use when studying mechanical and thermal loads acting on a cutting tool in 3D. Cutting forces, segmentation frequency and contact length show a good correlation with experimental results, thereby validating the numerical model. It seen that the serrated chip formation, gives rise to a periodic load acting on the cutting tool. This periodic behaviour has a drastic effect on both the maximal principal stresses and maximum effective stresses in the cutting tool. It can also be noted that the same behaviour as in [4] of the maximal principal stresses in the cutting tool is observed, where the maximal principal stresses in the engagement phase of a machining operation is studied.

This paper presents results of the pressure and thermal load in the cutting tool, regarding the dynamic behaviour due to a segmented chip formation. Both the mechanical and thermal load on the cutting tool has a close connection the to wear and fracture of the tool material. Both these loads could give rise to mechanical stresses in the cutting tool in this paper the maximal principal stress and maximum effective stress are examined. The reason for this is that
Fig. 14 Primary cutting force and maximal effective stress as a function of time

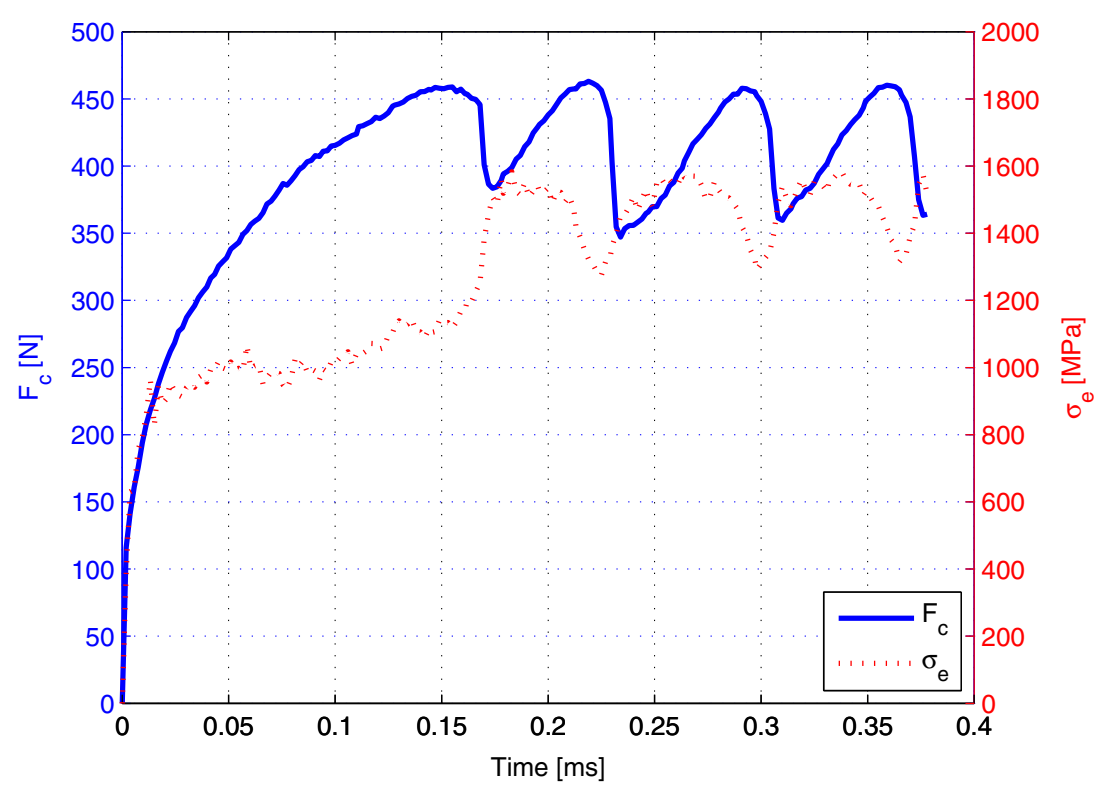


Fig. 15 Distribution of the temperature load at the rake face of the tool at the end of the simulation

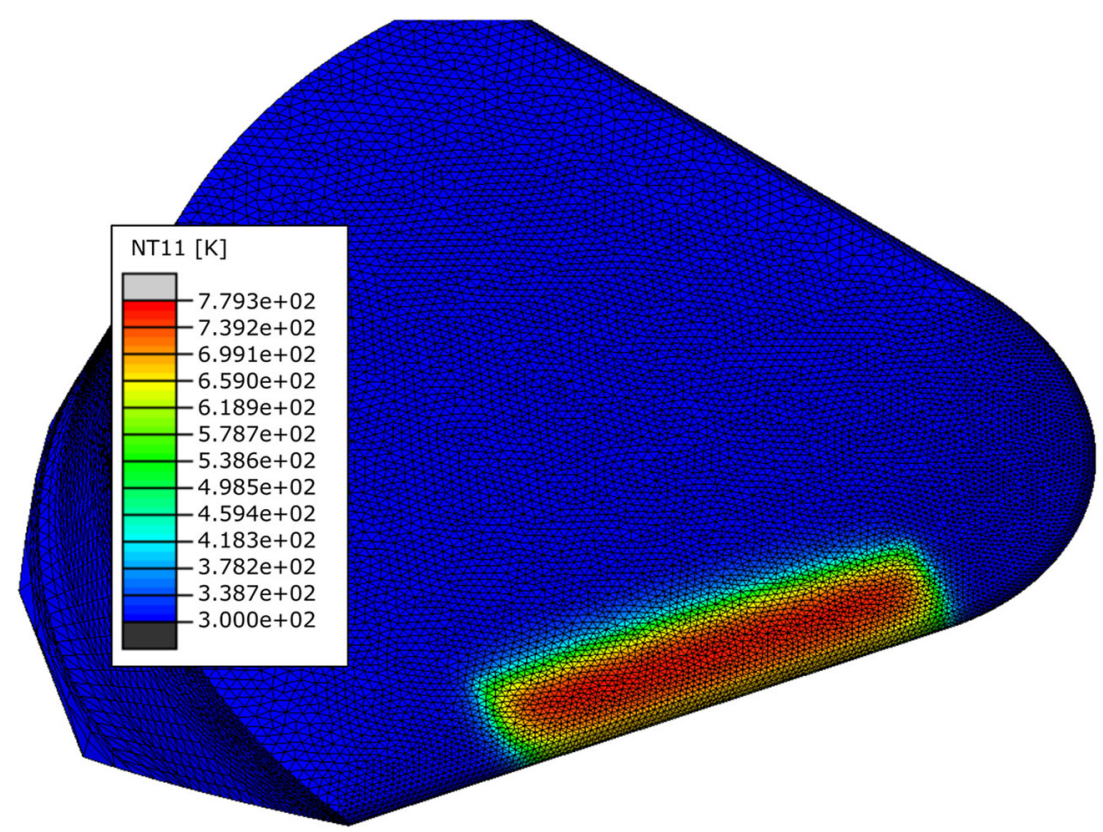

the occurrence of crack formation, tool chipping, flaking and breakage is mostly a function of the maximal principal stress in the cutting tool, commonly in combination with residual stresses in the tool due to the manufacturing sequences. When it comes to the maximal principal stress the distribution of the load is more important than the absolute value [34]. The risk of edge chipping and flaking is also related to the maximum effective stress in combination with the temperature field in the cutting tool, as seen in $[10,11]$. The thermal load softens the tool material which will influence the mechanical strength of the cutting tool; in future investigations, the Young's modulus of the tool

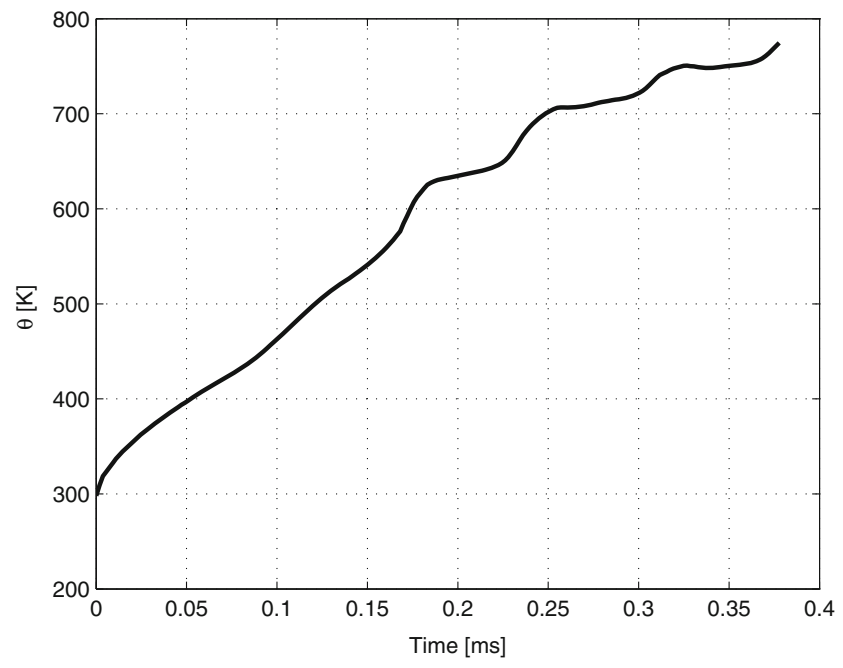

Fig. 16 Temperature for a node at the high temperature zone at the rake face as a function of time material will be temperature dependent in order to capture how this affects the maximal principal stress and maximum effective stress in the cutting tool.

In this discussion, it is also very important to realise that temperature and partly the pressure heavily increase the chemical tool deterioration. The chemical wear could commonly also result in a geometry change of the cutting tool, that results in stress concentrations especially interacting with the maximal principal stress. These problems are outside of the scope of this paper. But the mechanical and thermal loads presented here can be of value, when studying these phenomena.

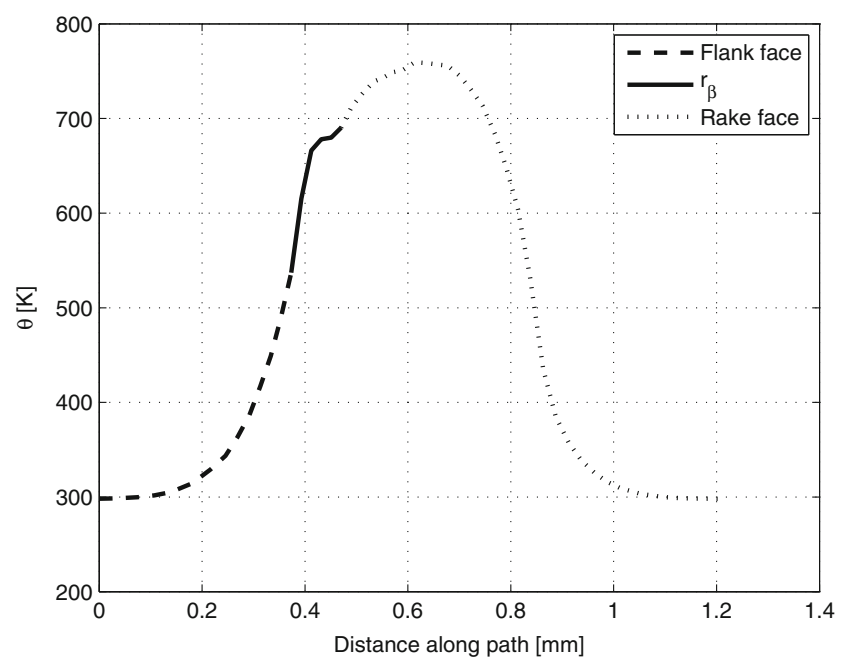

Fig. 17 Temperature for a node path along the middle cross section of the tool 


\section{Conclusions}

This study has clarified the influence of the pressure and thermal load on the maximal principal stress and the maximum effective stress in the cutting tool, in consideration of the dynamic behaviour due to a segmented chip formation. The following conclusions can be drawn from the work:

- The CEL formulation is a feasible and effective numerical simulation approach, for studying both a segmented chip formation and the loads subject to the cutting tool.

- A robust verification of the numerical simulation results has been done with experimental investigations. A good correlation was achieved for the cutting forces, contact length and segmentation frequency.

- The CEL formulation is able to predict the location and distribution of both the maximal principal stress and the maximum effective stress in the cutting tool.

- The location of temperature distribution on the cutting tool is also well predicted. But the model under predicts magnitude of the distribution compared to the steady state temperature of experimental results

Funding information This work was co-funded by the European Union's Horizon 2020 Research and Innovation Programme under Flintstone2020 project (grant agreement No 689279). It is also a part of the strategic research programme of the Sustainable Production Initiative SPI, involving cooperation between Lund University and Chalmers University of Technology.

Open Access This article is distributed under the terms of the Creative Commons Attribution 4.0 International License (http:// creativecommons.org/licenses/by/4.0/), which permits unrestricted use, distribution, and reproduction in any medium, provided you give appropriate credit to the original author(s) and the source, provide a link to the Creative Commons license, and indicate if changes were made.

\section{References}

1. (2004) Deforms - user manual. Scientific Forming Technologies Corporation, Columbus $(\mathrm{OH})$, USA

2. (2012) Classification and application of hard cutting materials for metal removal with defined cutting edges-designation of the main groups and groups of application. ISO 513:2012

3. (2014) Report on critical raw materials for the EU. https://ec.europa. eu/growth/sectors/raw-materials/specific-interest/critical_en, by the EU Ad-Hoc Working Group on Raw Materials

4. Agmell M, Ahadi A, Gutnichenko O, Ståhl JE (2016) The influence of tool micro-geometry on stress distribution in turning operations of AISI 4140 by FE analysis. In: The International journal of advanced manufacturing technology, $\mathrm{pp}$ 1-14. https://doi.org/10.1007/s00170-016-9296-7

5. Agmell M, Johansson D, Laakso SV, Ahadi A, Ståhl JE (2017) The influence the uncut chip thickness has on the stagnation point in orthogonal cutting. Procedia CIRP 58:13-18
6. Akbar F, Mativenga PT, Sheikh MA (2010) An experimental and coupled thermo-mechanical finite element study of heat partition effects in machining. Int J Adv Manuf Technol 46(5-8):491-507

7. Ambati R, Yuan H (2011) Fem mesh-dependence in cutting process simulations. Int J Adv Manuf Technol 53(1):313-323

8. Arsecularatne JA, Zhang L (2004) Assessment of constitutive equations used in machining. In: Key engineering materials, vol 274, Trans Tech Publ, pp 277-282

9. Bäker M, Rösler J, Siemers C (2002) A finite element model of high speed metal cutting with adiabatic shearing. Comput Struct 80(5):495-513

10. Bushlya V, Gutnichenko O, Zhou J, Avdovic P, Ståhl JE (2013) Effects of cutting speed when turning age hardened inconel 718 with pcbn tools of binderless and low-cbn grades. Mach Sci Technol 17(4):497-523

11. Chandrasekaran H, Nagarajan R (1977) Influence of flank wear on the stresses in a cutting tool. J Eng Indus 99(3):566-577

12. Chandrasekaran H, M'Saoubi R, Chazal H (2005) Modelling of material flow stress in chip formation process from orthogonal milling and split hopkinson bar tests. Mach Sci Technol 9(1):131145. https://doi.org/10.1081/MST-200051380

13. Danish M, Ginta TL, Habib K, Carou D, Rani AMA, Saha BB (2017) Thermal analysis during turning of az31 magnesium alloy under dry and cryogenic conditions. Int $\mathbf{J}$ Adv Manuf Technol 91(5):2855-2868. https://doi.org/10.1007/s00170-016-9893-5

14. Ducobu F, Arrazola PJ, Rivière-Lorphèvre E, de Zarate GO, Madariaga A, Filippi E (2017) The CEL method as an alternative to the current modelling approaches for Ti6Al4V orthogonal cutting simulation. Procedia CIRP 58:245-250

15. Ducobu F, Rivière-Lorphèvre E, Filippi E (2017) Mesh influence in orthogonal cutting modelling with the Coupled EulerianLagrangian (CEL) method. European J Mech-A/Solids

16. Heinstein M, Segalman D (1997) Simulation of orthogonal cutting with smooth particle hydrodynamics. Sandia National Laboratories

17. Hillerborg A, Modéer M, Petersson PE (1976) Analysis of crack formation and crack growth in concrete by means of fracture mechanics and finite elements. Cem Concr Res 6(6):773781

18. Johnson GR, Cook WH (1983) A constitutive model and data for metals subjected to large strains, high strain rates and high temperatures. In: Proceedings of the 7th International symposium on ballistics, vol 21. The Netherlands, pp 541-547

19. Johnson GR, Cook WH (1985) Fracture characteristics of three metals subjected to various strains, strain rates, temperatures and pressures. Eng Fract Mech 21(1):31-48

20. Klocke F, Döbbeler B, Peng B, Lakner T (2017) FE-simulation of the cutting process under consideration of cutting fluid. Procedia CIRP 58:341-346

21. Laakso SV, Zhao T, Agmell M, Hrechuk A, Ståhl JE (2017) Too sharp for its own good - tool edge deformation mechanisms in the initial stages of metal cutting. Procedia Manuf

22. Maranho C, Davim J (2012) Residual stresses in machining using fem. Rev Adv Mater Sci 30:267-272

23. M'Saoubi R, Outeiro J, Changeux B, Lebrun J, Dias AM (1999) Residual stress analysis in orthogonal machining of standard and resulfurized aisi 3161 steels. J Mater Process Technol 96(1):225-233. https://doi.org/10.1016/S0924-0136(99)00359-3. http://www. sciencedirect.com/science/article/pii/S0924013699003593

24. Nasr MN, Ammar MM (2017) An evaluation of different damage models when simulating the cutting process using FEM. Procedia CIRP 58:134-139

25. Nordgren A, Samani BZ, M'Saoubi R (2014) Experimental study and modelling of plastic deformation of cemented carbide tools in turning. Procedia CIRP 14:599-604 
26. Outeiro J, Umbrello D, M'Saoubi R (2006) Experimental and numerical modelling of the residual stresses induced in orthogonal cutting of aisi 3161 steel. Int J Mach Tools Manuf 46(14):17861794. https://doi.org/10.1016/j.ijmachtools.2005.11.013. http:// www.sciencedirect.com/science/article/pii/S0890695505003081

27. Özel T, Sima M, Anil KS (2010) Finite element simulation of high speed machining ti-6al-4v alloy using modified material models. Trans NAMRI/SME 50(11):943-960

28. Persson H, Agmell M, Bushlya V, Ståhl JE (2017) Experimental and numerical investigation of burr formation in intermittent turning of AISI 4140. Procedia CIRP 58:37-42

29. Sarin VK (2014) Comprehensive hard materials, vol 1. Elsevier Ltd

30. Schulze V, Zanger F (2011) Development of a simulation model to investigate tool wear in Ti-6Al-4V alloy machining. In: Advanced materials research, vol 223. Trans Tech Publ, pp 535-544

31. Serre I, Vogt JB (2009) Mechanical properties of a 316L/T91 weld joint tested in lead-bismuth liquid. Mater Des 30(9):37763783

32. Shen N, Ding H, Pu Z, Jawahir I, Jia T (2017) Enhanced surface integrity from cryogenic machining of az $31 \mathrm{~b}$ mg alloy: a physicsbased analysis with microstructure prediction. J Manuf Sci Eng 139(6):061,012
33. Skrzat A (2012) Application of coupled Eulerian-Lagrangian approach in metal forming simulations. Zeszyty Naukowe Politechniki Rzeszowskiej Mechanika 84 [284], nr 4:25-35

34. Ståhl JE (1986) Skäreggars spontanhaverier. Lund University, $\mathrm{PhD}$ thesis

35. Ståhl JE, SECO Tools A (2012) Metal cutting: theories and models. Lund University, pp 194-195

36. Steel A (2017) http://www.aksteel.com/pdf/markets_products/ stainless/austenitic/316_3161_data_sheet.pdf

37. Umbrello D (2008) Finite element simulation of conventional and high speed machining of Ti6Al4V alloy. J Mater Process Technol 196(1):79-87

38. Umbrello D, M'Saoubi R, Outeiro J (2007) The influence of Johnson-Cook material constants on finite element simulation of machining of AISI 316L steel. Int J Mach Tools Manuf 47(3):462-470

39. Vaz M, Owen D, Kalhori V, Lundblad M, Lindgren LE (2007) Modelling and simulation of machining processes. Arch Comput Methods Eng 14(2):173-204

40. Zhang Y, Outeiro J, Mabrouki T (2015) On the selection of Johnson-Cook constitutive model parameters for Ti-6Al-4V using three types of numerical models of orthogonal cutting. Procedia CIRP 31:112-117 